\title{
GLOBAL DUCTILITY OF DUAL STEEL FRAMES WITH REPLACEABLE DISSIPATIVE SHEAR WALLS
}

\author{
CALIN NEAGU - Assistant Professor, PhD, Politehnica University Timisoara, CMMC Department, \\ e-mail: calin.neagu@upt.ro
}

FLOREA DINU - Professor, PhD, Politehnica University Timisoara, CMMC Department, Romanian Academy, Timisoara Branch, CCTFA Research Center, e-mail: florea.dinu@upt.ro

DAN DUBINA - Professor, PhD, Member of the Romanian Academy, Politehnica University Timisoara, CMMC Department, Romanian Academy, Timisoara Branch, CCTFA Research Center, e-mail: dan.dubina@upt.ro

\begin{abstract}
The paper presents the results of a numerical program that was used to investigate the seismic performance of dual steel frames with dissipative shear walls. Nonlinear static and dynamic analyses were employed in order to evaluate the global ductility and the q factor for a twelve story building. The influence of the $\mathrm{q}$ factor on the estimated level of damage and post-earthquake intervention strategy was investigated. The dynamic analyses were conducted using two groups of accelerograms, selected to match the response spectra of two types of grounds. The numerical models were validated against experimental tests. The results show that $\mathrm{q}$ factor values adopted in design influence the level of damage. If re-centering capacity is properly controlled by design, the replacement of damaged walls can minimize the time and cost of intervention, thus supporting disaster resilience of buildings.
\end{abstract}

Keywords: dissipative steel shear wall, non-linear analysis, global ductility, q factor

\section{Introduction}

Typical steel plate shear wall systems (SPSW) may include singular steel plate systems (Fig. 1.a) or dual systems (Fig. 1.b). A coupled shear wall system is a particular dual system, where a coupling beam connects two shear wall bays (Fig. 1.c).

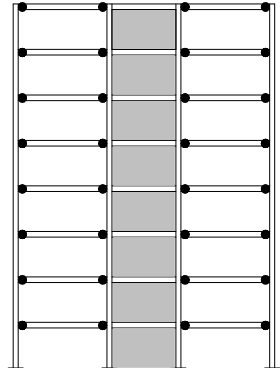

(a)

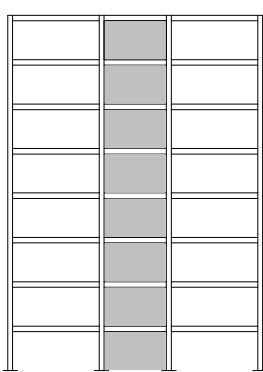

(b)

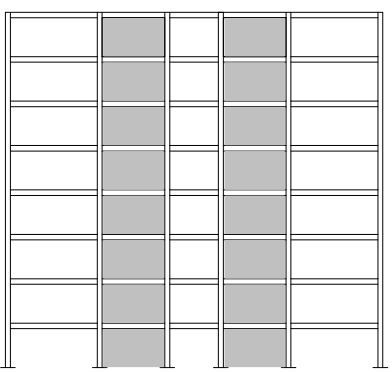

(c)

Fig. 1 - Steel shear wall systems: a) singular shear wall inside gravity frame (e.g. pinned); b) dual system with shear wall inside moment frame; c) dual system with coupling beams

The number of SPSW applications increased worldwide, especially in North America and Japan, where design rules were introduced in the codes. The application of SPSW system in Europe did not follow a similar trend. This can be justified also by a lack of consistent design provisions, e.g. no design rules can be found in seismic code EN 1998-1 [1]. If the design is based on response spectra approach, selection of appropriate $\mathrm{q}$ factor may require information from other codes, but this is not very straightforward. 
Buildings play a fundamental role in the disaster resilience of a community [2,3]. Thus, besides the initial cost of construction, a challenge for the dual SPSW system is the cost, time and technical difficulties of the intervention after a seismic event. Reducing the time and costs of post-earthquake intervention is a measure of seismic resilience. The initial cost of construction is lowered when large values of q factor are adopted in design, thus reducing the design base shear force; however, there are some drawbacks. Thus, under strong ground motions, this can result in significant damage in the dissipative members, i.e. beams and panels. In such cases, repair of the structure can be costly and technically demanding. Using lower values of q factors such that the energy is dissipated through steel shear walls only and the rest of the structure remain essentially elastic, can prove more efficient. After the earthquake, the elastic part of the structure allows the structure to return to / or close to initial position if the damaged walls are dismantled. The new walls can be easily uninstalled and replaced if bolting is used. When welding is used, these operations are much more difficult; also, for thin plates, the distortion of plates due to thermal effect induced by welding is avoided as well.

In order to address the issues presented above with regard to the performances of SPSW systems, a research program, that included experimental and numerical studies, was carried out at Politehnica University Timisoara, Laboratory of Steel Structures. The experimental study was performed on dual SPSW systems in order to quantify the global ductility (by means of q factor) and to observe the failure modes. Further, numerical studies were performed on SPSW structures that were designed according to Eurocodes. AISC2010 [4] provisions were employed, also, for initial design of the structure. Validation of the numerical models was done against experimental test results.

In the present paper, is investigated the seismic performance of a 12 story dual SPSW frame structure. The structure (Fig.2) is made of a three span moment resisting frame and two braced spans located inside the inner span. Two additional stanchions are placed as vertical boundary members for the walls, thus resulting in a link beam in the middle. This structural solution, proposed by authors represent an innovation in the field [5]. Nonlinear static and dynamic analyses were performed. For non-linear dynamic analysis, two groups of ground motions were selected, which are representative for two types of grounds. Ground motions were scaled to match the design spectra given in [1]. The numerical model was validated against test data [6].

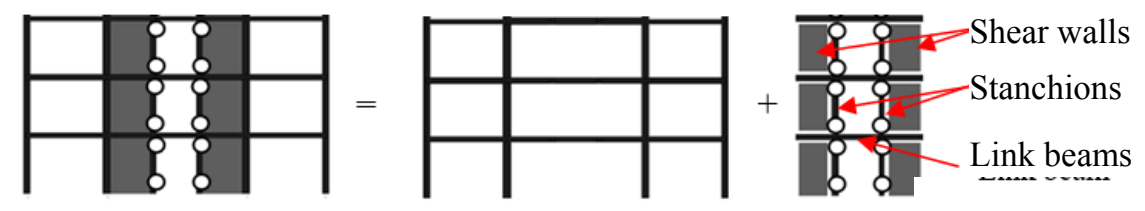

Fig. 2 - Dual SPSW with MRF, infill plates and stanchions

\section{Numerical investigation}

\subsection{Design of structure}

The structure was designed using Eurocodes and AISC [4]. According to EN1998 [1], the building site is characterized by a peak ground acceleration of $0.4 \mathrm{~g}$, with a corner period $\mathrm{T}_{\mathrm{C}}$ of $0.8 \mathrm{~s}$ (Type 1 response spectra and ground type D, see EN1998 [1]). The preliminary design was done considering a value of 5 for $\mathrm{q}$ factor. The configuration of the structure is shown in Fig. 2 . The design was done in two steps. In first step, SPSW was approximated by a vertical truss with equivalent tension braces (Fig. 3), in line with the AISC Seismic Provisions [2]. In second step, the equivalent structure with the vertical truss was designed according to Eurocodes ([1], [7], [8]) and AISC 2010 [4]. The cross sections of the equivalent braces were adjusted to meet the lateral drift requirements. 
According to capacity design principles in AISC [4], the horizontal (HBE) and vertical (VBE) boundary elements are designed to resist the maximum forces developed under the tension field action of the fully yielded panels. Axial forces, shear forces, and bending moments develop in the SPSW boundary elements because of the overall overturning, shear, and tension field action in the walls. VBEs and HBEs should remain essentially elastic under forces generated by fully yielded walls, but flexural hinges are allowed at the ends of HBEs. To prevent excessive deformation, leading to premature buckling under the pulling action of the walls, the minimum moment of inertia of the columns was calculated.

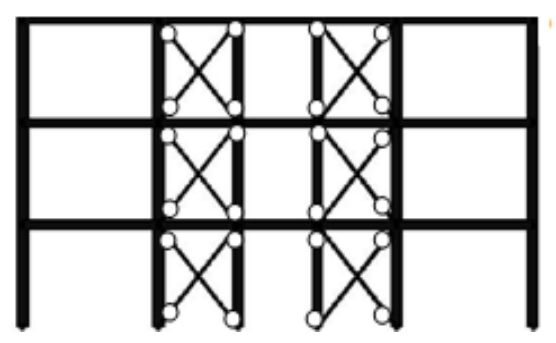

Fig. 3 - Equivalent structure with tension braces

After the equivalent structure with the vertical truss was designed and configured, the braces were replaced by steel walls. The thickness of the plates, $t_{w}$, was calculated using [2], for an assumed angle of inclination of the tension field $\alpha=45^{\circ}$, using the area of the equivalent tension braces A from step 1.

The geometry and sections of members are shown in Fig. 4. The exterior bays are $6 \mathrm{~m}$ long, the interior bay is $8 \mathrm{~m}$ long and has two braced spans of $2.8 \mathrm{~m}$ long. The story height is $3.5 \mathrm{~m}$. The beams, stanchions and columns were designed using S355 steel, which has a nominal yield strength $\mathrm{f}_{\mathrm{y}}$ of $355 \mathrm{~N} / \mathrm{mm}^{2}$. The plates were designed using $\mathrm{S} 235$ steel, which has a nominal yield strength $\mathrm{f}_{\mathrm{y}}$ of $235 \mathrm{~N} / \mathrm{mm}^{2}$. Cross section of beams, stanchions and columns were made of European $\mathrm{H}$ profiles.

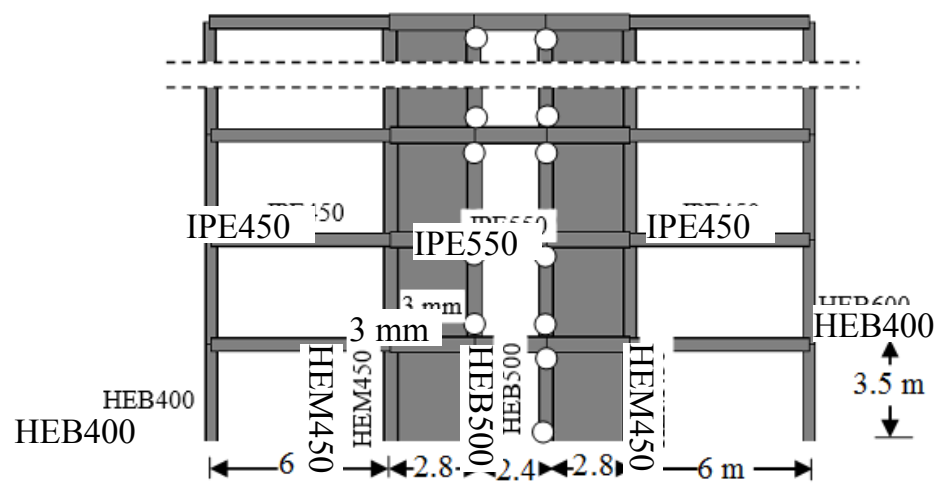

Fig. 4 - Geometry of the structure and size of the elements

\subsection{Analysis procedure}

The nonlinear static response of the structures was first analyzed using N2 method [9]. The target displacements for three limit states, i.e. Serviceability Limit State (SLS), Ultimate Limit State (ULS) and Collapse Prevention Limit State (CPLS), were calculated. The analysis used Type 1 elastic response spectrum for two ground types, A (stiff soil) and D (soft soil), respectively, see Fig. 5.

In order to estimate the structural performance under seismic loads, a non-linear incremental dynamic analysis IDA [10] was also employed, using two groups of accelerograms. Each group contained seven ground motions, and was scaled to match the same elastic response spectra that were 
presented in the previous section. The accelerations were averaged over a range of periods between $0,2 T_{1}$ and $T_{1}$, where $T_{1}$ is the fundamental period of the structure, see Fig. 6 . Note that the first three periods of the structure are $T_{1}=1.21 \mathrm{sec}, \mathrm{T}_{2}=0.34 \mathrm{sec}$ and $\mathrm{T}_{3}=0.17$, respectively. Then, each record was incrementally scaled to multiple levels and nonlinear dynamic analyses were run. Intensity of ground motion at SLS and CPLS is 0.5 , and 1.5 times the design acceleration corresponding to ULS. The analysis was stopped when numerical non-convergence was encountered or other limiting criteria were attained (e.g. exhaustion of deformation capacity in elements).

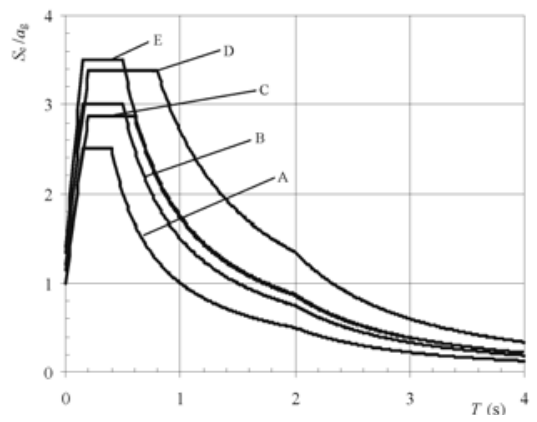

Fig. 5 - Type 1 elastic spectrum, 5\% damping, EN1998 [1]

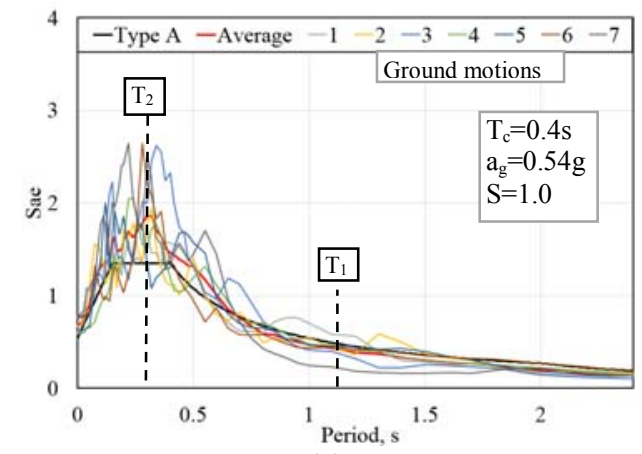

(a)

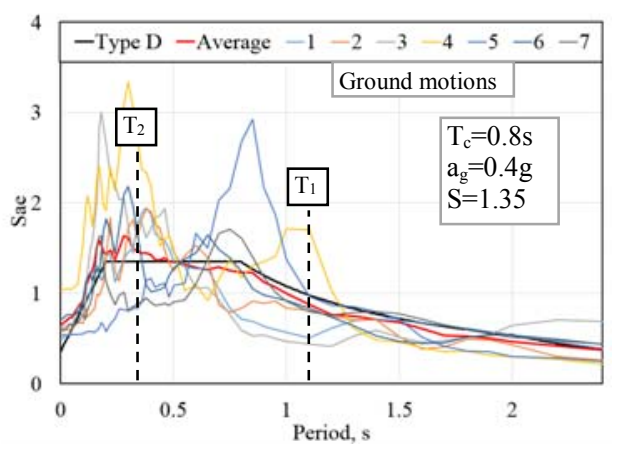

(b)

Fig. 6 - Ground motion records scaled to ground type A (a) and ground type D (b)

\subsection{Validation of the numerical model}

Validation of the numerical models was done against results of experimental tests carried out in [5]. General-purpose SAP2000 software was used for analysis [11]. Thus, beams and columns were modeled with plastic hinges located at both ends. A simplified model, based on the equivalent strip model developed by Driver et al. (1998) [12] (Fig. 7.a), was used to model the walls.

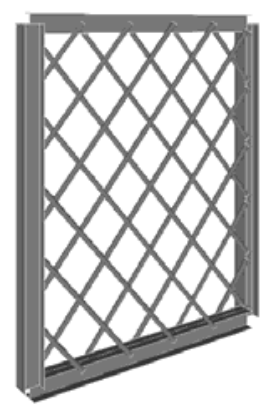

(a)

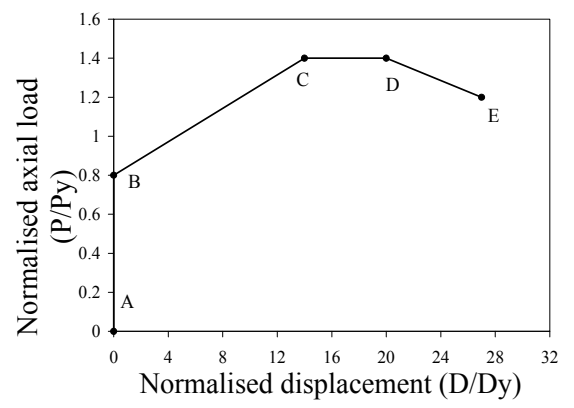

(b)

Fig. 7 - a) Strip model; b) Tension only plastic hinge

The equivalent strip model replaces the steel walls with 10 pin-ended strips inclined at an angle $\alpha$ with respect to vertical (strips oriented in both directions) with tension only plastic hinges (Fig. 7.b) (for equation of $\alpha$ see [5]). The area of the strip, $A_{s}$, is taken according to AISC code [4]. 
The accuracy of the equivalent strip model can be seen in Fig. 8, which shows the force displacement curves under monotonic and cyclic loading. The strip model predicts with good accuracy the entire behavior of the system, including the softening branch and pinching effect (for cyclic, only). The small differences can be attributed to imperfections in testing set-up and contribution of beam to column connections (gusset plate effect).
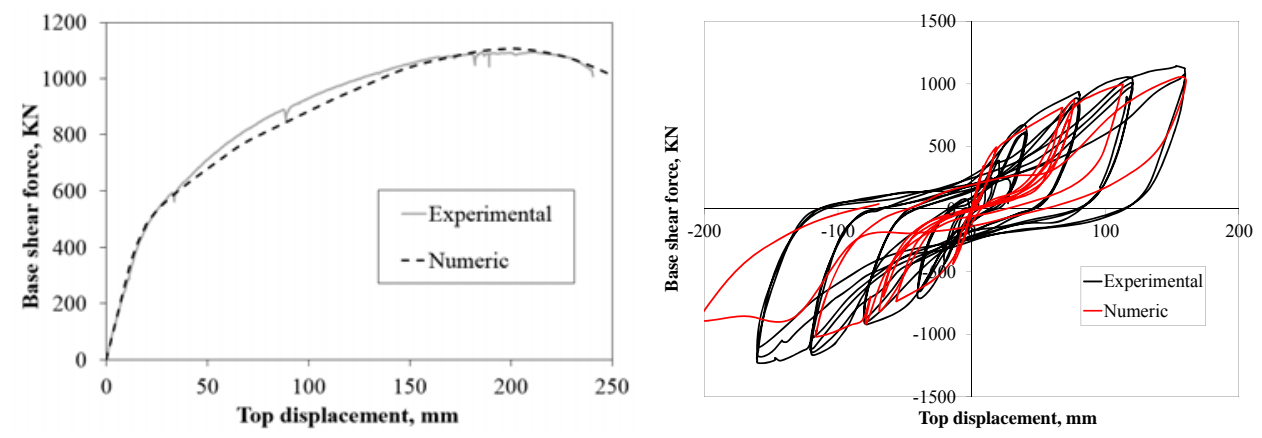

Fig. 8 - Numerical vs. experimental force-displacement curves

\subsection{Results of nonlinear analysis}

\subsubsection{Static analysis}

A nonlinear static (pushover) analysis was performed first. The pattern of the lateral loads was inverted triangle (first mode). Fig. 9 shows the capacity curve and the target displacement at SLS, ULS and CPLS for the two types of grounds. The target displacement for the three limit states corresponding to ground type A are $0.146 \mathrm{~m}, 0.292 \mathrm{~m}$ and $0.439 \mathrm{~m}$ respectively, while the target displacement corresponding to ground type D are $0.292 \mathrm{~m}, 0.585 \mathrm{~m}$ and $0.877 \mathrm{~m}$ respectively. In case of ground type A, no plastic hinges were recorded up to SLS. At ULS the plastic hinges are located mainly in the walls, while at CPLS plastic hinges are also developed in un-braced spans, see Fig. 10. In case of ground type D, plastic hinges developed in walls, before reaching SLS. The plastic hinges in un-braced spans started to develop before reaching ULS (Fig. 10).

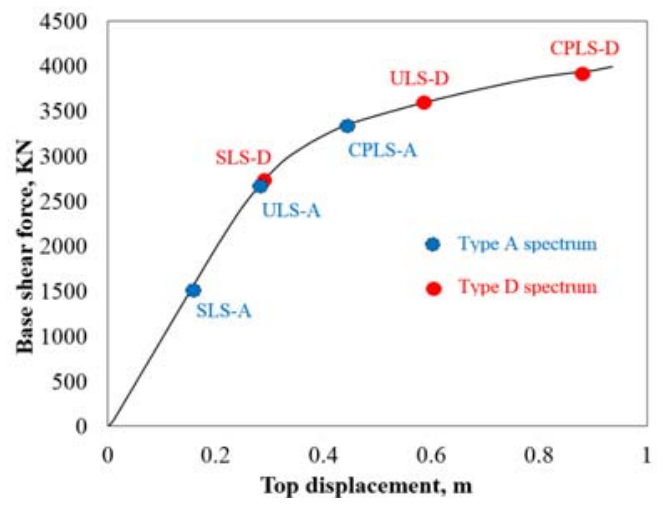

Fig. 9 - Capacity curve and target displacements
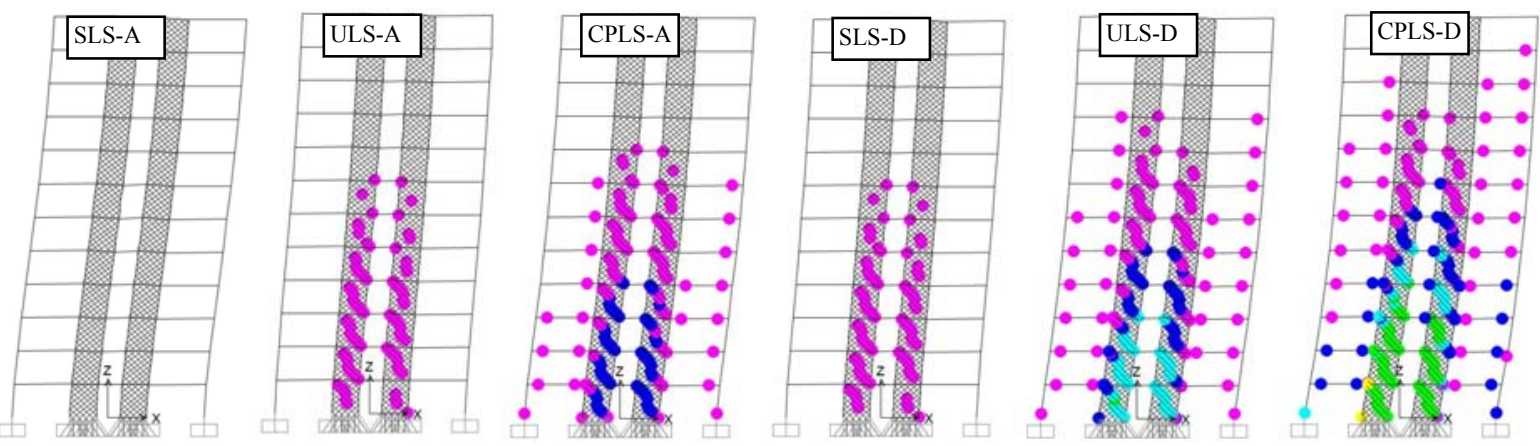

Fig. 10 - Plastic mechanism in structures for ground type A and D 


\subsubsection{Dynamic analysis}

The results of incremental non-linear dynamic analysis are presented in terms of inter-story drift
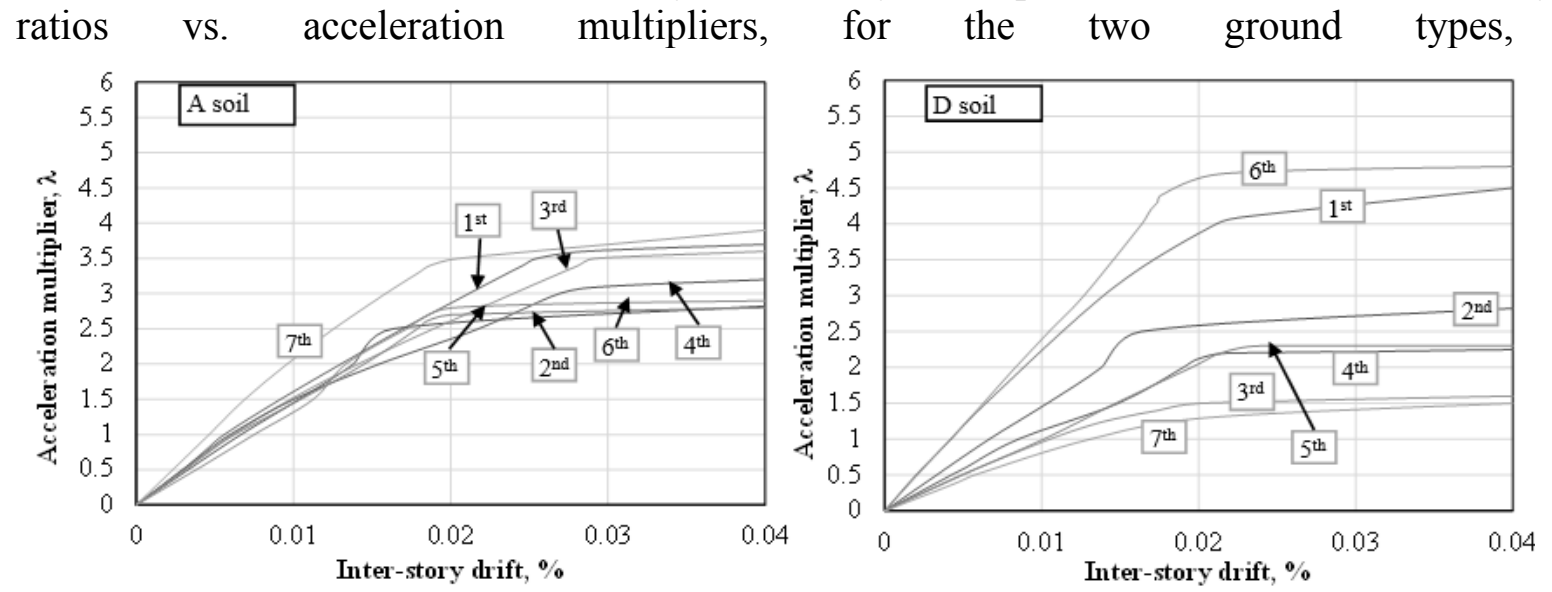

Fig. 11 In case of ground type A, the structure attains the collapse prevention criteria for all ground motions. In case of ground type $\mathrm{D}$, the structure does not attain collapse prevention criteria for 2 ground motions.
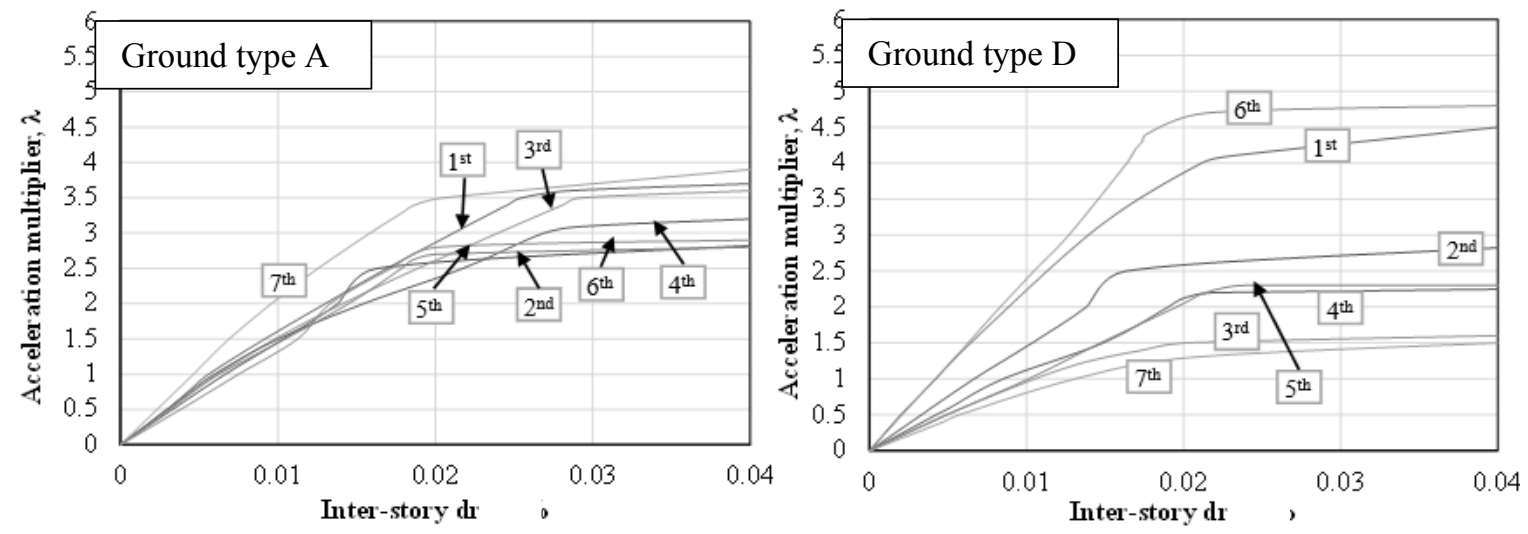

Fig. 11 - Incremental dynamic analysis curves

Fig. 12 shows the development of plastic hinges corresponding to $3^{\text {rd }}$ ground motion. At ULS, for either ground types, the plastic hinges are mainly developed in walls, with no / or incipient damage in un-braced spans. This indicates that the MR frames remain essentially elastic and poses the restoring force that may be needed in case of post-earthquake intervention for replacing the damaged walls [13]. At CPLS, for ground type A, the damage is concentrated in the walls, with few plastic deformations outside the walls, at the base of the internal columns. In this state the structure can still be re-centered if the panels with permanent plastic deformations are dismantled. But, for ground type $\mathrm{D}$, the plastic mechanism is complete, with severe deformations in walls and beams, and the safety against collapse is limited.
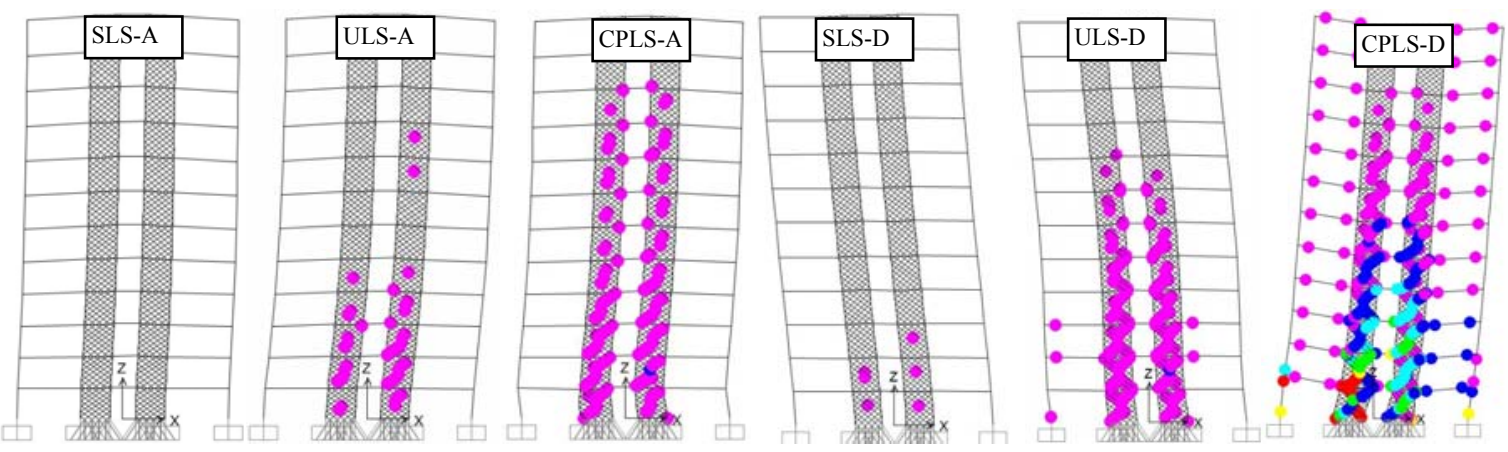

Fig. 12 - Plastic mechanism development for $3^{\text {rd }}$ ground motion for ground type A (left) and D (right) 
One of the most important parameters associated with the global performance of the SPSW systems is the behavior factor $\mathrm{q}$. The behavior factor $\mathrm{q}$ is expressed as a product of the ductility factor, $\mathrm{q}_{\mu}$, and the over-strength factor, $\mathrm{q}_{\mathrm{s}}$. The over-strength factor may vary significantly and is affected by the contribution of gravity loads, material over-strength, structural redundancy, etc. EN 1998 indicates a value of 1.5 for $\mathrm{q}_{\mathrm{s}}$, to account for over-strength. The ductility factor is more important when the dissipation capacity is of concern, and will be investigated separately. On the other hand, different ductility factors (e.g. partial ductility factors [14] can be associated with different performance levels. In this study three ductility factors, corresponding to different degree of damage, were calculated:

- ductility factor corresponding to first yielding in MRF, $\mathrm{q}_{\mu, \mathrm{r}}$ : this factor is associated to the point where MRF is still elastic and able to provide the full re-centering capacity. $\mathrm{q}_{\mu, \mathrm{r}}$ is defined as the ratio between the acceleration multiplier leading to first yielding in MRF, $\lambda \mathrm{r}$, and the acceleration multiplier leading to first yielding, $\lambda_{1}$;

- ductility factor corresponding to collapse prevention, $\mathrm{q}_{\mu, \mathrm{c}} \cdot \mathrm{q}_{\mu, \mathrm{c}}$ is defined as the ratio between the acceleration multiplier corresponding to CPLS, $\lambda_{c}$, and the acceleration multiplier leading to first yielding, $\lambda_{1}$. The value of the multiplier $\lambda_{c}$ can be considered equal to 1.5 ;

- maximum or total ductility factor, $\mathrm{q}_{\mu, \mathrm{m}}$ : defined as the ratio between the acceleration multiplier leading to collapse, $\lambda_{\mathrm{m}}$, and the acceleration multiplier leading to first yielding, $\lambda_{1}$. This is the value that is actually used in design and is specified in seismic codes.

If the three ductility factors, $\mathrm{q}_{\mu}$, are multiplied by the over-strength factor of 1.5 , the total $\mathrm{q}$ factors are obtained, resulting in $\mathrm{q}_{\mu, \mathrm{r}}, \mathrm{q}_{\mu, \mathrm{c}}$ and $\mathrm{q}_{\mu, \mathrm{m}}$.

First two q factors, i.e. $\mathrm{q}_{\mu, \mathrm{r}}$ and $\mathrm{q}_{\mu, \mathrm{c}}$, may be called as "partial q factors", as they do not account for the maximum dissipation capacity of the structure.

Table 1 shows the values of the acceleration multipliers and q factors. For ground type A, the mean value of the re-centering ductility factor, $\mathrm{q}_{\mu, \mathrm{r}}$, is 1.92 , for $\mathrm{q}_{\mu, \mathrm{c}}$ is 1.94 and the maximum factor, $\mathrm{q}_{\mu, \mathrm{m}}$, amounts 4.04 . For ground type $\mathrm{D}, \mathrm{q}_{\mu, \mathrm{r}}$ amounts $2.04, \mathrm{q}_{\mu, \mathrm{c}}$ amounts 2.66 and maximum factor, $\mathrm{q}_{\mu, \mathrm{m}}$, is 3.70 .

Table 1

Acceleration multipliers and q factor values from nonlinear dynamic analysis

\begin{tabular}{|c|c|c|c|c|c|c|c|c|c|c|}
\hline \multirow{2}{*}{$\begin{array}{l}\text { Ground } \\
\text { type }\end{array}$} & \multirow{2}{*}{ Parameter } & \multicolumn{7}{|c|}{ Accelerograms } & \multirow{2}{*}{$\underset{\text { mean value }}{\mathrm{q}_{\mu}}$} & \multirow{2}{*}{$\begin{array}{c}\mathrm{q} \\
{\left[\mathrm{q}_{\mu} \times \mathrm{q}_{\mathrm{s}}\right]}\end{array}$} \\
\hline & & 1 & 2 & 3 & 4 & 5 & 6 & 7 & & \\
\hline \multirow{7}{*}{ A } & $\lambda_{1}$ & 0.8 & 0.7 & 0.8 & 0.7 & 0.7 & 0.8 & 1.0 & & \\
\hline & $\lambda_{\mathrm{r}}$ & 1.5 & 1.4 & 1.5 & 1.5 & 1.5 & 1.5 & 1.5 & & \\
\hline & $\lambda_{\mathrm{c}}$ & 1.5 & 1.5 & 1.5 & 1.5 & 1.5 & 1.5 & 1.5 & & \\
\hline & $\lambda_{\mathrm{m}}$ & 3.6 & 2.8 & 3.6 & 3.1 & 2.7 & 2.9 & 3.4 & & \\
\hline & $\mathrm{q}_{\mu, \mathrm{r}}$ & 1.9 & 2.0 & 1.9 & 2.1 & 2.1 & 1.9 & 1.5 & 1.92 & 2.88 \\
\hline & $\mathrm{q}_{\mu, \mathrm{c}}$ & 1.9 & 2.1 & 1.9 & 2.1 & 2.1 & 1.9 & 1.5 & 1.94 & 2.91 \\
\hline & $\mathrm{q}_{u, \mathrm{~m}}$ & 4.5 & 4.0 & 4.5 & 4.4 & 3.9 & 3.6 & 3.4 & 4.04 & 6.06 \\
\hline \multirow{7}{*}{$\mathrm{D}$} & $\lambda_{1}$ & 1.0 & 0.5 & 0.4 & 0.6 & 0.5 & 1.3 & 0.4 & & \\
\hline & $\lambda_{\mathrm{r}}$ & 2.5 & 1.0 & 1.0 & 1.0 & 0.9 & 2.4 & 0.8 & & \\
\hline & $\lambda_{\mathrm{c}}$ & 1.5 & 1.5 & 1.5 & 1.5 & 1.5 & 1.5 & 1.5 & & \\
\hline & $\lambda_{\mathrm{u}}$ & 4.1 & 1.5 & 1.4 & 2.2 & 2.3 & 4.6 & 1.4 & & \\
\hline & $\mathrm{q}_{\mu, \mathrm{r}}$ & 2.5 & 2.0 & 2.5 & 1.7 & 1.8 & 1.8 & 2.0 & 2.04 & 3.06 \\
\hline & $\mathrm{q}_{\mu, \mathrm{c}}$ & 1.5 & 3.0 & 3.8 & 2.5 & 3.0 & 1.2 & 3.8 & 2.66 & 3.99 \\
\hline & $\mathrm{q}_{\mu, \mathrm{m}}$ & 4.1 & 3.0 & 3.5 & 3.7 & 4.6 & 3.5 & 3.5 & 3.70 & 5.55 \\
\hline
\end{tabular}

Partial $\mathrm{q}$ factor, $\mathrm{q}_{\mu, \mathrm{r}}$, is close to 3.0 for both ground types. The minimum value of partial factor, $\mathrm{q}_{\mu, \mathrm{c}}$, is also close to 3.0, and corresponds to ground type A. The total $\mathrm{q}$ factor (design value) ranges between 5.55 and 6.06. One may see that, if partial $\mathrm{q}$ factor, $\mathrm{q}_{\mu, \mathrm{r}}$, is used in design instead of total q factor, the initial cost of the structure will increase, due to higher design base shear forces. However, the amount of steel weight increase is not very straightforward, because other factors need also to be considered, e.g. overstrength, steel grade. For example, if the system 
investigated in the study is designed using a partial $\mathrm{q}$ factor $\mathrm{q}_{\mu, \mathrm{r}}$, equal to 3 , the increase of the steel weight is about $11 \%$. However, this increase may be fully justified if costs associated to the repairs and loss of operation after an earthquake are taken into account.

\section{Conclusions}

Behavior of dual SPSW with link beams has been investigated. Nonlinear static and dynamic analysis were employed on a 12 story building frame in order to evaluate the seismic response. Seven ground motions and two ground types were used in the numerical simulations. Apart from the q factor given by the codes, a partial q factor called "re-centering q factor", was also introduced. This factor is particularly important if the re-centering capacity is of interest in design. Thus, if partial $\mathrm{q}$ factor $\mathrm{q}_{\mu, \mathrm{r}}$ is used in design instead of total $\mathrm{q}$ factor, the design base shear force is larger, resulting is higher demands for strength, and, consequently in higher construction costs. However, the structure has a larger re-centering capacity, and the time, cost and technical difficulties for the post-earthquake interventions are reduced correspondingly. Obviously, a reduced time to recovery, obtained using a lower q design, implicitly means lower structural and non-structural damage, thus enhanced seismic resilience. The design for such a resilience oriented design will be taken by the owners of the building, of course.

Further studies will include more structural typologies and case studies, on the aim to provide $\mathrm{q}$ factor values for better seismic protection but including the resilience performance as well.

\section{Acknowledgement}

This work was supported by the strategic grant POSDRU/159/1.5/S/137070 (2014) of the Ministry of National Education, Romania, co-financed by the European Social Fund - Investing in People, within the Sectorial Operational Programme Human Resources Development 2007-2013.

\section{References}

[1] EN 1998-1 (2004). Eurocode 8: Design of structures for earthquake resistance - Part 1: General rules, seismic actions and rules for buildings, CEN.

[2] Bruneau, M., E. Chang, S. E., Eguchi, R. T., Lee, G. C., O’Rourke, T. D., Reinhorn, A. M., Shinozuka, M., Tierney, K., Wallace, W. A. \& Von Wintergeldt, D. (2004). A framework to quantitatively assess and enhance the seismic resilience of communities, $13^{\text {th }}$ World Conference on Earthquake Engineering, August 1-6, 2004, Vancouver, B.C., Canada.

[3] Main, J. A., McAllister, T. P., Lew, H. S., Sadek, F. H., Duthinh, D., Chapman, R. E \&.Bao, Y. (2011). Measures of Building Resilience and Structural Robustness Project, National Institute of Standard and Technology, U.S. Department of Commerce.

[4] ANSI/AISC 341-10 (2010). Seismic provisions for structural steel buildings, American Institute for Steel Construction.

[5] Neagu C. (2011). Multi-story building frames stiffened with dissipative shear walls, PHD. Thesis, Universitatea Politehnica Timisoara, Facultatea de Constructii, Departamentul de Construcţii Metalice şi Mecanica Construcţiilor, ISBN 978-606-554-270-9.

[6] Dubina, D. \& Dinu F. (2013). Experimental evaluation of dual frame structures with thin-walled steel panels, Thin-Walled Structures, 78,57-69, DOI: 10.1016/j.tws.2014.01.001.

[7] EN 1993-1-1 (2005). Eurocode 3: Design of steel structures - Part 1-1: General rules and rules for buildings, CEN.

[8] EN1993-1-8 (2005). Eurocode 3: Design of steel structures, Part 1-8: Design of joints, CEN.

[9] Fajfar, P. (2000). A nonlinear analysis method for performance-based seismic design, Earthquake Spectra, 16(3), 573-92. DOI: http://dx.doi.org/10.1193/1.1586128.

[10] Vamvatsikos, D. \& Cornell, C. A. (2002). Incremental Dynamic Analysis, Earthquake Engineering and Structural Dynamics, 31(3), 491-514, Published online in Wiley, DOI: 10.1002/eqe.141.

[11] SAP2000 analysis reference manual.

[12] Driver, R. G., Kulak, G. L., Elwi, A. E. \& Kennedy, D. J. L, (1998b). FE and Simplified Models of Steel Plate Shear Wall, ASCE Journal of Structural Engineering, 124(2), 121-130, ISSN: 0733-9445.

[13] Dubina, D., Stratan, A. \& Dinu, F. (2011). Re-centering capacity of dual-steel frames, Steel Construction: Design and Research, 2(4), 73-81, Published online in Wiley, DOI: 10.1002/stco.201110011.

[14] Dinu, F., Grecea, D. \& Dubina, D. (2003). Partial q-factor values for performance based design of MR frames, STESSA 2003 - Behaviour of steel structures in seismic areas, 9-12 June, 2003, Napoli, Italy. 